\title{
Smoking, breastfeeding, physical inactivity, contact with animals, and size of the family influence the risk of inflammatory bowel disease: A Slovak case-control study
}

United European Gastroenterology Journal 1(2) 109-119 (C) Author(s) 2013 Reprints and permissions: sagepub.co.uk/journalsPermissions.nav DOI: $10.1177 / 2050640613478011$ ueg.sagepub.com

(S)SAGE

\author{
Tibor Hlavaty, Jozef Toth, Tomas Koller, Anna Krajcovicova, \\ Stanislava Oravcova, Zuzana Zelinkova and Martin Huorka
}

\begin{abstract}
Background: The aetiology of inflammatory bowel disease (IBD) is not known but is likely to involve a combination of genetic predisposition and environmental risk factors. Smoking has been associated consistently with a higher risk of Crohn's disease (CD), while appendectomy and smoking appear to diminish the risk of ulcerative colitis (UC). The roles of other environmental factors are unclear. The aim of the present study was to evaluate the association of CD and UC with several environmental risk factors.

Methods: This case-control study included 338 patients (190 CD, 148 UC) and 355 controls. All subjects completed a detailed questionnaire regarding breastfeeding duration, history of helminthic infections, allergic diseases, appendectomy, household size, housing type, contact with specific domestic animals, physical activity, and smoking. Associations between risk factors and $C D$ and UC were investigated by univariate and multivariate analysis.

Results: On multivariate analysis, $\mathrm{CD}$ associated with smoking at diagnosis (odds ratio, $0 \mathrm{R}, 3.7,95 \% \mathrm{Cl} 2.2-6.2 ; p<0.001$ ), being breastfed for $<6$ months (OR $2.7,95 \% \mathrm{Cl} 1.7-4.4 ; p<0.001)$, and less than two childhood sporting activities weekly (OR 2.7, $95 \% \mathrm{Cl} 1.5-5.0 ; p<0.001)$ and inversely associated with frequent contact with cats in childhood $\left(0 \mathrm{R} 0.6,95 \% \mathrm{Cl} 0.4^{-}\right.$ $0.9 ; p<0.03)$. UC associated with less than two sporting weekly activities in childhood (OR 2.0,95\% $\mathrm{Cl} 1.1-3.5, p=0.02)$, fewer household members in childhood $(0 \mathrm{R} 0.8,95 \% \mathrm{Cl} 0.7-0.98, p=0.03)$, and being breastfed for $<6$ months (OR 1.7, $95 \% \mathrm{Cl} 1.02-2.8, p=0.04)$. A composite environmental risk index for CD revealed that 47 and $14 \%$ of the controls and patients with CD had no risk factors, respectively, and that 14 and $38 \%$ of the controls and patients with CD had at least two risk factors, respectively.

Conclusion: $C D$ and UC associated with infrequent childhood sports activities and short breastfeeding. Furthermore, CD associated with smoking and infrequent contact with animals in childhood. UC associated with a smaller family size in childhood.
\end{abstract}

Keywords

Crohn's disease, ulcerative colitis, inflammatory bowel disease, etiology, enviromental risk factors, smoking, breastfeeding, contact with animals, physical activity, case-control study

Received: 23 November 2012; accepted: 16 January 2013

\section{Background}

Inflammatory bowel diseases (IBD) are chronic inflammatory conditions of the gastrointestinal tract and include Crohn's disease (CD) and ulcerative colitis (UC).

Despite extensive research into the aetiology of IBD, their cause remains unknown. At present, it is widely believed that IBD is induced by a multifactorial interplay of three elements, namely genetic susceptibility, mucosal immunity, and environmental risk

University Hospital Bratislava, Bratislava, Slovakia

Corresponding author:

Tibor Hlavaty, Gastroenterology Unit, Department of Internal Medicine V, University Hospital Bratislava, Ruzinovska 6, SK-82606 Bratislava, Slovakia. Email: tibor.hlavaty2@gmail.com 
factors. ${ }^{1}$ Since the discovery of the NOD2 gene in 2001, there has been major progress in the research into IBD genetics. ${ }^{2}$ Genetic studies have identified several dozens of susceptibility genes; these genes are mostly involved in the mucosal immune defence mechanisms against microorganisms that invade the mucosa. ${ }^{3}$ Infectious aetiologies have also been studied extensively but a single causative microbial agent has never been confirmed.

The dramatic 4-fold increase in the incidences of both $\mathrm{CD}$ and $\mathrm{UC}$ in the past decades cannot be attributed solely to genetic predisposition because this cannot change that fast. It is more likely that environmental risk factors play an important role in triggering IBD in genetically predisposed individuals.

A number of environmental risk factors were suggested to be associated with CD and/or UC, including: smoking; appendectomy; oral contraception; insufficient breastfeeding; a diet rich in sugar, fat, and protein; a diet poor in vegetable and fruits; a fast food diet; dietary components, such as saccharin, carrageen, margarine, and cola; insufficient contact with farm animals; a sedentary lifestyle; left-handedness; psychosocial stress factors; dietary microparticles of aluminum, titanium, and silicon oxides, calcium phosphate; and refrigeration. ${ }^{4-11}$

The only replicated and widely recognized environmental risk factor for $\mathrm{CD}$ is smoking, ${ }^{12}$ while only smoking and appendectomy have been shown consistently to protect from UC. ${ }^{9,12}$ Further analysis of the other proposed environmental factors have yielded inconsistent or contradictory results. Thus, the environmental trigger(s) of IBD remain unresolved and further studies are needed.

The aim of the present study was to evaluate the association of $\mathrm{CD}$ and $\mathrm{UC}$ with several known and suspected environmental risk factors. To do so, a multifactorial analysis was performed.

\section{Methods}

This case-control study involved a cohort of patients who were followed up between 2008 and 2009 in the IBD Centre of the Department of Internal Medicine, Division of Gastroenterology and Hepatology, University Hospital Bratislava, Ruzinov.

\section{Patient cohort}

The patient cohort consisted of 338 consecutive patients with IBD: 190 patients with $\mathrm{CD}$ and 148 patients with UC. The diagnosis of all patients was based on conventional clinical, endoscopic, radiological, and histological criteria. Before the next visit at our department, the patients completed a paper version of the questionnaire in our department $(n=145)$ or were asked during their visit to complete the same questionnaire via a secured internet site upon subsequent email notification (193 patients responded of 205 notified).

The demographic data and clinical characteristics of the patients were recorded. The clinical data were categorized according to the Montreal classification. ${ }^{13}$

\section{Control group}

The control group consisted of 355 healthy volunteers who were age- and sex-matched with the patient group. Family members of patients with IBD were excluded. The healthy volunteers were mostly recruited from the healthy accompanying persons of non-IBD patients or the medical students and staff members of our department and their acquaintances. The control group subjects completed the questionnaire discussed above.

The clinical and demographic characteristics of the patient and control groups are shown in Table 1.

\section{The questionnaire}

The questionnaire that was completed by both cohorts consisted of 44 questions concerning socioeconomic status, medical and surgical history, and exposure to environmental risk factors, namely the length of the breastfeeding period, history of helminth infections, history of allergic diseases, history of frequent respiratory diseases, history of appendectomy and tonsillectomy, concomitant medication, family history, number of older and total siblings, type of housing in childhood and at present, type of housing neighbourhood, contact with particular animals at least once weekly in childhood and at present (frequent contact), education level, profession, and frequency of sporting activities in childhood and at present. There were also questions on smoking at the time of diagnosis and at present.

\section{Statistical analysis}

Statistical analyses were performed by using appropriate statistical tests in the statistical software SPSS 18.0 (IBM SPSS, Chicago, IL, USA). In terms of nominal variables the patient group was compared to the control group by using the chi-squared test with Yate's correction. The parametric data were tested with Student's t-test or ANOVA techniques, while the nonparametric data were tested with a non-parametric test (Mann-Whitney $U$-test). Categorical ordinal variables were also tested with the Mann-Whitney $U$-test. Multivariate testing was performed in $\mathrm{CD}$ and $\mathrm{UC}$ cohorts separately by using multivariate logistic 
Table 1. Demographic and clinical characteristics of the patient and control groups

\begin{tabular}{|c|c|c|c|}
\hline Characteristic & $\begin{array}{l}\text { Controls } \\
(n=355)\end{array}$ & $\begin{array}{l}\text { Crohn's disease } \\
(n=190)\end{array}$ & $\begin{array}{l}\text { Ulcerative colitis } \\
(n=148)\end{array}$ \\
\hline Female/male & $188 / 167(53 / 47)$ & $112 / 78(59 / 41)$ & $95 / 53(64 / 36)$ \\
\hline Age (years) & $28(16-81)$ & $31(16-87)$ & $34(14-73)$ \\
\hline Age at diagnosis (years) & - & $24.7(4-63)$ & $28.2(5-71)$ \\
\hline $0-16$ years & - & $21(12)$ & $13(9)$ \\
\hline $17-40$ years & - & $138(78)$ & $95(68)$ \\
\hline $41+$ years & - & $17(10)$ & $31(22)$ \\
\hline Disease duration (years) & - & $3.8(0-40.9)$ & $4.3(0-38.8)$ \\
\hline \multicolumn{4}{|l|}{ Location of disease } \\
\hline \multicolumn{4}{|l|}{ Crohn's disease } \\
\hline Ileum (L1) & - & $63(36)$ & - \\
\hline Colon (L2) & - & $39(22)$ & - \\
\hline Ileum and colon (L3) & - & $71(40)$ & - \\
\hline Upper GIT (L4) & - & $3(2)$ & - \\
\hline Perianal involvement & - & $51(27)$ & 0 \\
\hline \multicolumn{4}{|l|}{ Ulcerative colitis } \\
\hline Proctitis (E1) & - & - & $27(20)$ \\
\hline Left-sided (E2) & - & - & $63(47)$ \\
\hline Pancolitis (E3) & - & - & $44(33)$ \\
\hline \multicolumn{4}{|l|}{ Behaviour in CD } \\
\hline Inflammatory (B1) & - & $103(54)$ & - \\
\hline Stenosing(B2) & - & $34(18)$ & - \\
\hline Fistulizing (B3) & - & $53(28)$ & - \\
\hline Abdominal IBD surgery & - & $40(21)$ & $5(3)$ \\
\hline Total colectomy & - & $2(5)$ & $3(60)$ \\
\hline Partial colectomy & - & $5(12)$ & $1(20)$ \\
\hline Ileocaecal resection & - & $28(70)$ & 0 \\
\hline Segmental ileal resection & - & $4(10)$ & 0 \\
\hline Other & - & $1(3)$ & $1(20)$ \\
\hline
\end{tabular}

Values are median (range) or $n(\%)$. CD, Crohn's disease; IBD, inflammatory bowel disease.

regression method as well as classification tree method according to in-built algorithms in SPSS 18.0. ${ }^{14}$ $p$-values $<0.05$ were considered to be statistically significant. In multiple univariate analyses, the $p$-values were adjusted using the Bonferroni correction.

\section{Ethical considerations}

All subjects provided written permission to use the collected data for research purposes.

\section{Results}

The associations between the potential risk factors and $\mathrm{CD}$ or UC were determined by performing univariate analyses and then by performing multivariate logistic regression and classification tree analyses.
Univariate analyses of childhood environmental risk factors

Univariate analyses of the childhood environmental factors (Table 2) revealed that the control group was significantly less likely to have been breastfed for less than 6 months than either the CD cohort $(p<0.001)$ or the UC cohort $(p=0.04)$. These data are displayed in Figure 1. The IBD patients were also more likely to have grown up in smaller families $(p=0.03)$. Correspondingly, the control subjects had an average family size sharing a household in childhood of $3.8 \pm 1.4$, whereas the equivalent family sizes in the $\mathrm{CD}$ and UC cohorts were $3.5 \pm 1.4(p=0.006)$ and $3.3 \pm 1.5(p<0.001)$, respectively. The third observation was that the $\mathrm{CD}$ cohort was less likely to have frequent contact with animals in childhood than the controls 
Table 2. Comparison of the inflammatory bowel disease cohorts with the control group in terms of childhood factors

\begin{tabular}{|c|c|c|c|}
\hline \multirow[b]{2}{*}{ Factor } & \multirow[b]{2}{*}{ Controls $(n=355)$} & \multicolumn{2}{|l|}{ Cohort } \\
\hline & & $\mathrm{CD}(n=190)$ & UC $(n=148)$ \\
\hline Breastfeeding duration (months) & $8.0 \pm 5.6$ & $7.1 \pm 7.4$ & $8.0 \pm 7.5$ \\
\hline $0-5$ months & $94(32)$ & $69(53.5)^{\star *}$ & $42(43.8)^{\star \star}$ \\
\hline $6-12$ months & $164(56)$ & $44(34)$ & $41(43)$ \\
\hline $12+$ months & $35(12)$ & $16(12)$ & $13(14)$ \\
\hline \multicolumn{4}{|l|}{ Family } \\
\hline People in family & $3.8 \pm 1.4$ & $3.5 \pm 1.4^{*}$ & $3.3 \pm 1.5^{\star \star}$ \\
\hline Children in family & $1.9 \pm 1.3$ & $1.6 \pm 1.3^{\star}$ & $1.6 \pm 1.1^{\star}$ \\
\hline Older siblings & $1.0 \pm 1.1$ & $1.0 \pm 1.4$ & $0.9 \pm 1.0$ \\
\hline \multicolumn{4}{|l|}{ Infections in childhood (yes/no) } \\
\hline Frequent respiratory infection & $127 / 187(40 / 60)$ & $61 / 88(41 / 59)$ & $40 / 78(34 / 66)$ \\
\hline Ascaris infection & $83 / 212(28 / 72)$ & 40/105 (28/72) & $35 / 82(30 / 70)$ \\
\hline Any parasitic infection & $16 / 267(6 / 94)$ & $7 / 126$ (5/95) & $8 / 109(7 / 93)$ \\
\hline \multicolumn{4}{|l|}{ Settlement in childhood } \\
\hline Village & $122(35)$ & $61(33)$ & $54(37)$ \\
\hline Town $<20,000$ & $57(16)$ & $34(18)$ & $30(20)$ \\
\hline City $>20,000$ & $169(49)$ & $92(49)$ & $64(43)$ \\
\hline Frequent contact with animals in childhood & $267(75)$ & $121(64)^{\star \star}$ & $107(72)$ \\
\hline Dogs & $221(62)$ & $98(52)^{\star}$ & $87(59)$ \\
\hline Cats & $161(45)$ & $68(36)^{*}$ & $68(46)$ \\
\hline Poultry & $157(44)$ & $70(37)$ & $54(37)$ \\
\hline Cattle & $36(10)$ & $10(5)^{\star}$ & $11(7)$ \\
\hline Horses & $19(5)$ & $6(3)$ & $9(6)$ \\
\hline Pigs & $81(23)$ & $37(20)$ & $35(24)$ \\
\hline Small rodents & $51(14)$ & $28(15)$ & $16(11)$ \\
\hline \multicolumn{4}{|l|}{ Sporting activity in childhood } \\
\hline Never & $21(6)$ & $19(10)^{\star \star}$ & $15(10)^{*}$ \\
\hline Once per week or less & $35(10)$ & $45(24)^{\star \star}$ & $25(17)^{\star}$ \\
\hline Twice and more per week & $291(84)$ & $121(65)^{\star \star}$ & $106(73)^{\star}$ \\
\hline
\end{tabular}

Values are mean $\pm S D$ or $n(\%)$. *Statistical difference vs. controls $(p<0.05)$. ${ }^{*}$ Statistical difference vs. controls $(p<0.001)$. CD, Crohn's disease; UC, ulcerative colitis.

$(p=0.005)$. The patients with $\mathrm{CD}$ had less frequent contacts with $\operatorname{dogs}(p=0.02)$, cats $(p=0.03)$, and cattle $(p=0.049)$. Finally, the control subjects did more sports in childhood: i.e. were significantly less likely to undergo infrequent sporting activity (less than twice a week) than the CD $(p<0.001)$ and UC cohorts $(p=0.02)$. These data are shown in Figure 2.

\section{Univariate analyses of socioeconomic environmental risk factors}

The analysis of the socioeconomic environmental factors is shown in Table 3. The controls were more likely to have a university education than the $\mathrm{CD}$ and $\mathrm{UC}$ cohorts.

\section{Univariate analyses of smoking and comorbidities}

Finally, the smoking and medical comorbidities of the cohorts were analysed (Table 4). The patients in the CD and UC groups were more likely to have been smoking at the time of diagnosis than the control subjects ( $p<0.001$ for both comparisons). The patients in the $\mathrm{CD}$ cohort were also more likely to have undergone an appendectomy than the control subjects $(p<0.001)$. The UC cohort patients were also more likely to have depression than the control subjects $(p=0.01)$.

\section{Multivariate analyses in $C D$}

Next, the risk factors associated with $\mathrm{CD}$ were subjected to multivariate logistic regression analysis 


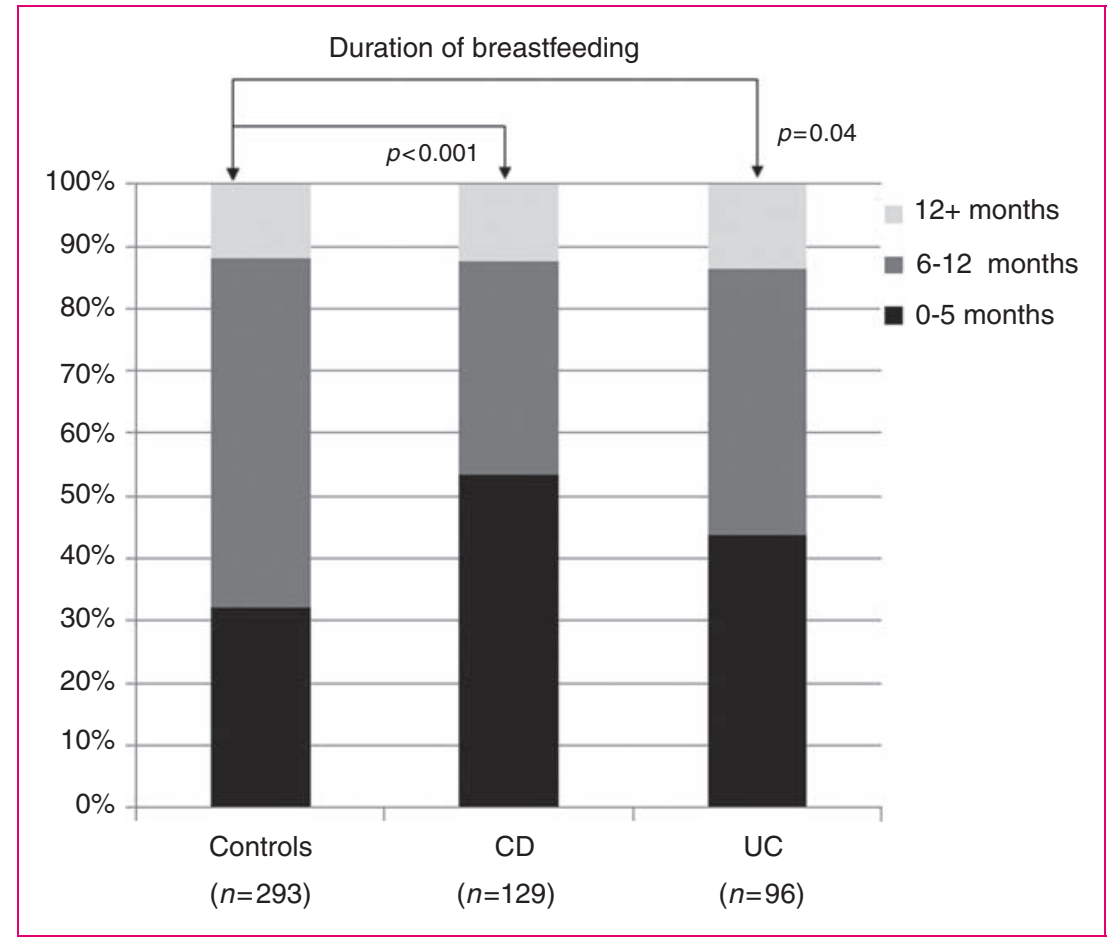

Figure 1. Breastfeeding duration in the inflammatory bowel disease cohorts and the control group. $p$-values are relative to the control group. CD, Crohn's disease; UC, ulcerative colitis.

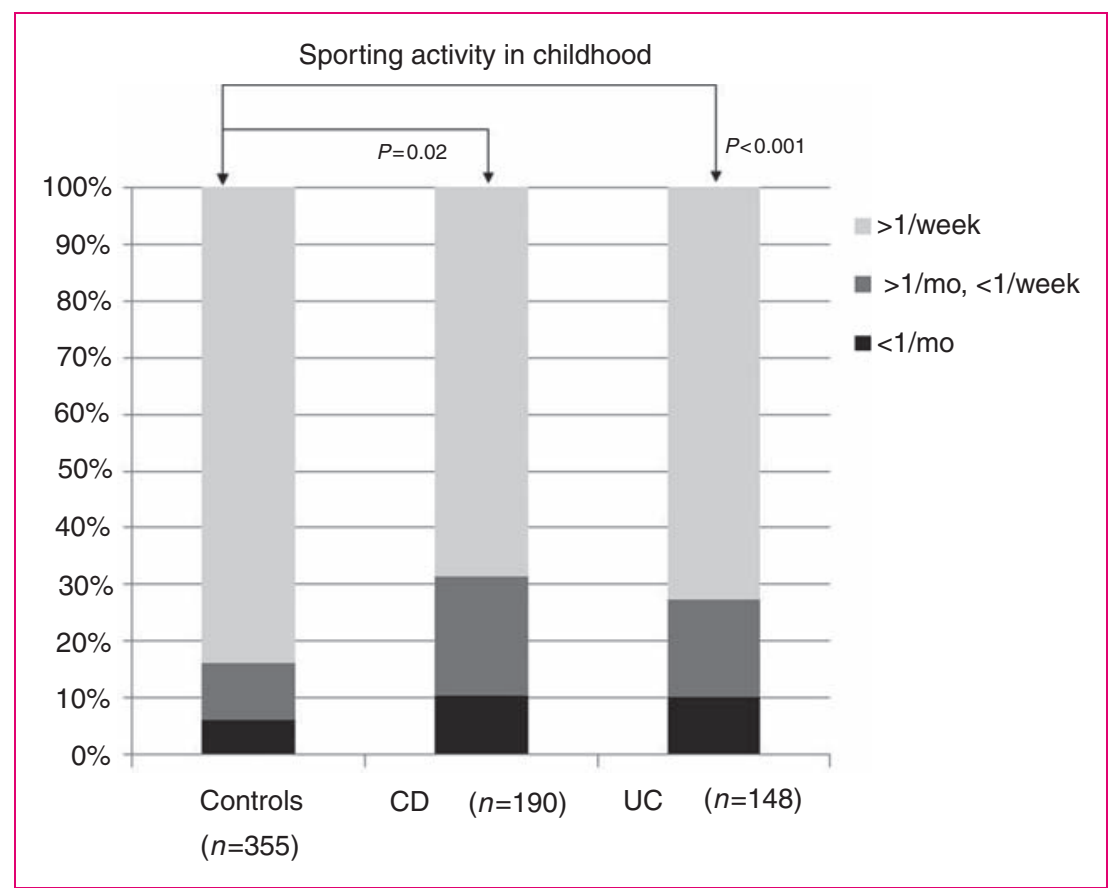

Figure 2. Sporting activity in childhood in the inflammatory bowel disease cohorts and the control group. $p$-values are relative to the control group. CD, Crohn's disease; UC, ulcerative colitis. 
Table 3. Comparison of the IBD cohorts with the control group in terms of socioeconomic factors

\begin{tabular}{|c|c|c|c|}
\hline \multirow[b]{2}{*}{ Factor } & \multirow{2}{*}{$\begin{array}{l}\text { Controls } \\
(n=355)\end{array}$} & \multicolumn{2}{|l|}{ Cohort } \\
\hline & & $\mathrm{CD}(n=190)$ & UC $(n=148)$ \\
\hline \multicolumn{4}{|l|}{ Settlement } \\
\hline Village & $86(24)$ & $52(28 \%$ & $44(30)$ \\
\hline Town $<20,000$ & $33(9)$ & $33(18)$ & $17(12)$ \\
\hline City $>20,000$ & $235(66)$ & $103(55)$ & $87(59)$ \\
\hline \multicolumn{4}{|l|}{ Housing type } \\
\hline Apartment & $196(57)$ & $115(64)$ & $88(61)$ \\
\hline Family house & $135(39)$ & $62(34)$ & $55(38)$ \\
\hline Other & $13(4)$ & $4(2)$ & $2(1)$ \\
\hline \multicolumn{4}{|l|}{ Education } \\
\hline Primary & $55(16)$ & $32(17)$ & $27(19)$ \\
\hline Secondary & $98(28)$ & $80(44)$ & $63(43)$ \\
\hline University & $200(57)$ & $72(39)^{\star *}$ & $56(38)^{\star \star}$ \\
\hline \multicolumn{4}{|l|}{ Profession } \\
\hline Manual work & $49(15)$ & $40(23)^{*}$ & $39(27)^{*}$ \\
\hline Sedentary work & $290(86)$ & $136(77)$ & $108(74)$ \\
\hline
\end{tabular}

Values are $n(\%) .{ }^{*}$ Statistical difference vs. controls $(p<0.05) .{ }^{* \star}$ Statistical difference vs. controls $(p<0.001)$. CD, Crohn's disease; UC, ulcerative colitis.

Table 4. Comparison of the IBD cohorts with the control group in terms of smoking and comorbidities

\begin{tabular}{|c|c|c|c|}
\hline \multirow[b]{2}{*}{ Factor } & \multirow{2}{*}{$\begin{array}{l}\text { Controls } \\
(n=355)\end{array}$} & \multicolumn{2}{|l|}{ Cohort } \\
\hline & & $\mathrm{CD}(n=190)$ & UC $(n=148)$ \\
\hline Smoking at diagnosis & $69(19)$ & $80(42)^{\star \star}$ & $53(36)^{\star \star}$ \\
\hline $\begin{array}{l}\text { Daily number of } \\
\text { cigarettes at Dx }\end{array}$ & $2.3 \pm 6.0$ & $4.3 \pm 6.2^{\star \star}$ & $4.1 \pm 7.2^{\star}$ \\
\hline $\begin{array}{c}\text { Duration of smoking } \\
\text { at Dx (years) }\end{array}$ & $4.1 \pm 8.6$ & $2.5 \pm 5.0$ & $3.4 \pm 6.9$ \\
\hline Appendectomy & $25(7.0)$ & $41(21.6)^{\star \star}$ & $10(6.8)$ \\
\hline Tonsillectomy & $64(18)$ & $35(18)$ & $24(16)$ \\
\hline Depression & $12(3)$ & $13(7)$ & $13(9)^{*}$ \\
\hline Eczema & $71(20)$ & $41(22)$ & $30(20)$ \\
\hline Allergic rhinoconjunctivitis & $66(19)$ & $35(18)$ & $24(16 \%$ \\
\hline Allergy: self reported & $112(32)$ & $67(35)$ & $51(35)$ \\
\hline Pollen & $51(14)$ & $34(18)$ & $24(16)$ \\
\hline Dust mite & $34(10)$ & $18(10)$ & $15(10)$ \\
\hline Food & $21(6)$ & $15(8)$ & $10(7)$ \\
\hline
\end{tabular}

Values are mean $\pm S D$ or $n(\%)$. *Statistical difference vs. controls $(p<0.05) .{ }^{*}$ Statistical difference vs. controls $(p<0.001) . C D$, Crohn's disease; Dx, diagnosis; UC, ulcerative colitis.

(Table 5). Four independent environmental risk factors for $\mathrm{CD}$ were identified: smoking at the time of diagnosis (OR 3.7, 95\% CI 2.2-6.2), being breastfed for less than 6 months (OR 2.7, 95\% CI 1.7-4.4), doing sporting activities less than twice a week in childhood (OR 2.7, 95\% CI 1.5-5.0), and infrequent contact with cats in childhood (OR 1.7, 95\% CI 1.1-2.8).

Classification tree analysis is a multivariate statistical analysis that is based on the classification of cohorts into subgroups according to significant input variables at each node. This maximizes the composite predictive value. The results of the classification tree analysis are shown in Figure 3. The data showed that $39 \%$ of the control cohort subjects did not have any risk factors; only $9 \%$ of the CD cohort patients had no risk factors.

\section{Multivariate analyses in UC}

The risk factors associated with UC were subjected to multivariate logistic regression analysis (Table 6). Three independent environmental risk factors for $\mathrm{UC}$ were identified: being breastfed for less than months (OR $1.7,95 \%$ CI 1.02-2.8), less than two sporting activities per week in childhood (OR 2.0, 95\% CI 1.1-3.5), and the number of household members in childhood (OR $0.8,95 \%$ CI $0.7-0.98$ ).

\section{Environmental risk index}

The three significant variables that associated with $C D$ in multivariate analyses, namely smoking at diagnosis (OR 3.7), being breastfed for less than 6 months (OR 2.7), and less than two sporting activities per week in childhood (OR 2.7), were then combined into a new composite index called the environmental risk index (ERI). In this index, the presence of each particular risk factor adds one point for the subject. Thus, when a subject has no risk factors, the ERI is 0 , whereas the presence of all three risk factors yields an ERI of 3 . In the ERI $=0$ group, there were $137(47 \%)$ controls and $18(14 \%)$ patients with $\mathrm{CD}$. In the ERI $=1$ group, there were $112(39 \%)$ controls and $60(48 \%)$ patients with $\mathrm{CD}$. In the $\mathrm{ERI}=2$ group, there were $37(13 \%)$ controls and $42(33 \%)$ patients with CD. In the $\mathrm{ERI}=3$ group, there were three $(1 \%)$ controls and six $(5 \%)$ patients with $\mathrm{CD}$. The data are shown in Figure 4.

Finally, the theoretical prevalence of CD in particular ERI subgroup was calculated on the basis of the data observed in this study. The calculated theoretical prevalence of $\mathrm{CD}$ in particular ERI subgroups are shown in Table 7. The increasing prevalence of risk factors in the population increased the theoretical prevalence of $\mathrm{CD}$ from 30 in the no-risk population to 124 (one risk factor), 259 (two risk factors), and 505 (all three risk factors). 
Table 5. Multivariate logistic regression of environmental factors associated with Crohn's disease

\begin{tabular}{|c|c|c|c|c|c|c|c|}
\hline \multirow[b]{2}{*}{ Step } & \multirow[b]{2}{*}{ Variable } & \multirow[b]{2}{*}{ B } & \multirow[b]{2}{*}{ SE } & \multirow[b]{2}{*}{$p$-value } & \multirow{2}{*}{$\begin{array}{l}\text { OR } \\
(\operatorname{Exp}(B))\end{array}$} & \multicolumn{2}{|c|}{$95 \% \mathrm{Cl}$ for $\operatorname{EXP}(\mathrm{B})$} \\
\hline & & & & & & Lower & Upper \\
\hline \multirow[t]{11}{*}{$1 \mathrm{a}$} & Smoking at diagnosis & 1.290 & 0.266 & 0.000 & 3.634 & 2.156 & 6.127 \\
\hline & Breastfeeding for less than 6 months & 0.961 & 0.252 & 0.000 & 2.615 & 1.596 & 4.287 \\
\hline & Frequent contact with animals in childhood & 0.212 & 0.421 & 0.615 & 1.236 & 0.541 & 2.823 \\
\hline & Contact with dogs in childhood & 0.070 & 0.368 & 0.850 & 1.072 & 0.521 & 2.207 \\
\hline & Contact with cats in childhood & 0.604 & 0.328 & 0.065 & 1.829 & 0.962 & 3.478 \\
\hline & Contact with poultry in childhood & -0.511 & 0.330 & 0.121 & 0.600 & 0.314 & 1.145 \\
\hline & Contact with cattle in childhood & 0.918 & 0.578 & 0.112 & 2.505 & 0.807 & 7.779 \\
\hline & Less than two sporting activities per week in childhood & 0.999 & 0.322 & 0.002 & 2.717 & 1.445 & 5.106 \\
\hline & Number of siblings & -0.049 & 0.104 & 0.636 & 0.952 & 0.776 & 1.168 \\
\hline & Number of household members & -0.067 & 0.093 & 0.467 & 0.935 & 0.779 & 1.121 \\
\hline & Constant & -2.586 & 0.705 & 0.000 & 0.075 & & \\
\hline \multirow[t]{5}{*}{$7 a$} & Smoking at diagnosis & 1.314 & 0.260 & 0.000 & 3.722 & 2.235 & 6.200 \\
\hline & Breastfed for less than 6 months & 0.999 & 0.247 & 0.000 & 2.716 & 1.674 & 4.409 \\
\hline & Contact with cats in childhood & 0.549 & 0.253 & 0.030 & 1.732 & 1.054 & 2.845 \\
\hline & Less than twosporting activities per week in childhood & 1.004 & 0.314 & 0.001 & 2.730 & 1.477 & 5.048 \\
\hline & Constant & -2.186 & 0.270 & 0.000 & 0.112 & & \\
\hline
\end{tabular}

Step 1a, input-independent variables; Step 7a, output-independent variables; B, coefficient in the correlation equation; SE, standard error of B; $p$, level of statistical significance for a particular factor; OR, odds ratio, $\mathrm{Cl}$, confidence interval for the odds ratio.

\section{Discussion}

In the present study, a wide range of potential environmental risk factors (48 in total) were analysed in $\mathrm{CD}$ and UC cohorts and an age- and sex-matched control group. Multivariate analyses revealed that $\mathrm{CD}$ associated with four independent environmental risk factors, namely smoking at the time of diagnosis, less than two sporting activities per week in childhood, being breastfed for less than 6 months, and frequent contact with cats in childhood. In addition, UC associated significantly with three independent environmental risk factors, namely less than two sporting activities per week in childhood, the number of household members in childhood, and being breastfed for less than 6 months.

\section{Limitations}

This study had three major limitations. Firstly, there were only 190 and 148 patients with CD and UC, respectively. While this size is comparable to those in similar studies ${ }^{15-18}$ and allows for good univariate analyses, it limits the scope of multivariate analyses to study interactions between factors to a maximum of two or three factors. The second limitation was the recall bias of the data, especially with regard to the early childhood data and multiple questions. It is difficult to design a retrospective study that solves this type of error. ${ }^{19}$ However, we believe there is no reason to think that the recall bias was different in the control and study cohorts. The third possible source of error was interaction bias of particular factors. ${ }^{20}$ In the present study, a strong interaction was observed between contact with different animals in childhood; there was also covariance between the number of siblings and the size of the family in childhood.

\section{Smoking}

Smoking was the strongest $\mathrm{CD}$-associated risk factor in the present study. Our observation is in line with those of several studies, including a recent meta-analysis. ${ }^{12}$ The effects of smoking on IBD have been reviewed extensively elsewhere. ${ }^{6}$ It is possible that smoking promotes $C D$ by suppressing immune functions and/or reducing intestinal motility. ${ }^{21,22}$ Contrary to most published data, we have found also more smokers in the UC cohort than among controls. Although we do not have a clear explanation, it might be that the UC patients were older at diagnosis or had longer duration of disease and that in the past the smoking rate in Slovakia was much higher than today.

\section{Sporting activity}

Less than two sporting activities per week in childhood was a risk factor for both $\mathrm{CD}$ and $\mathrm{UC}$ in the 


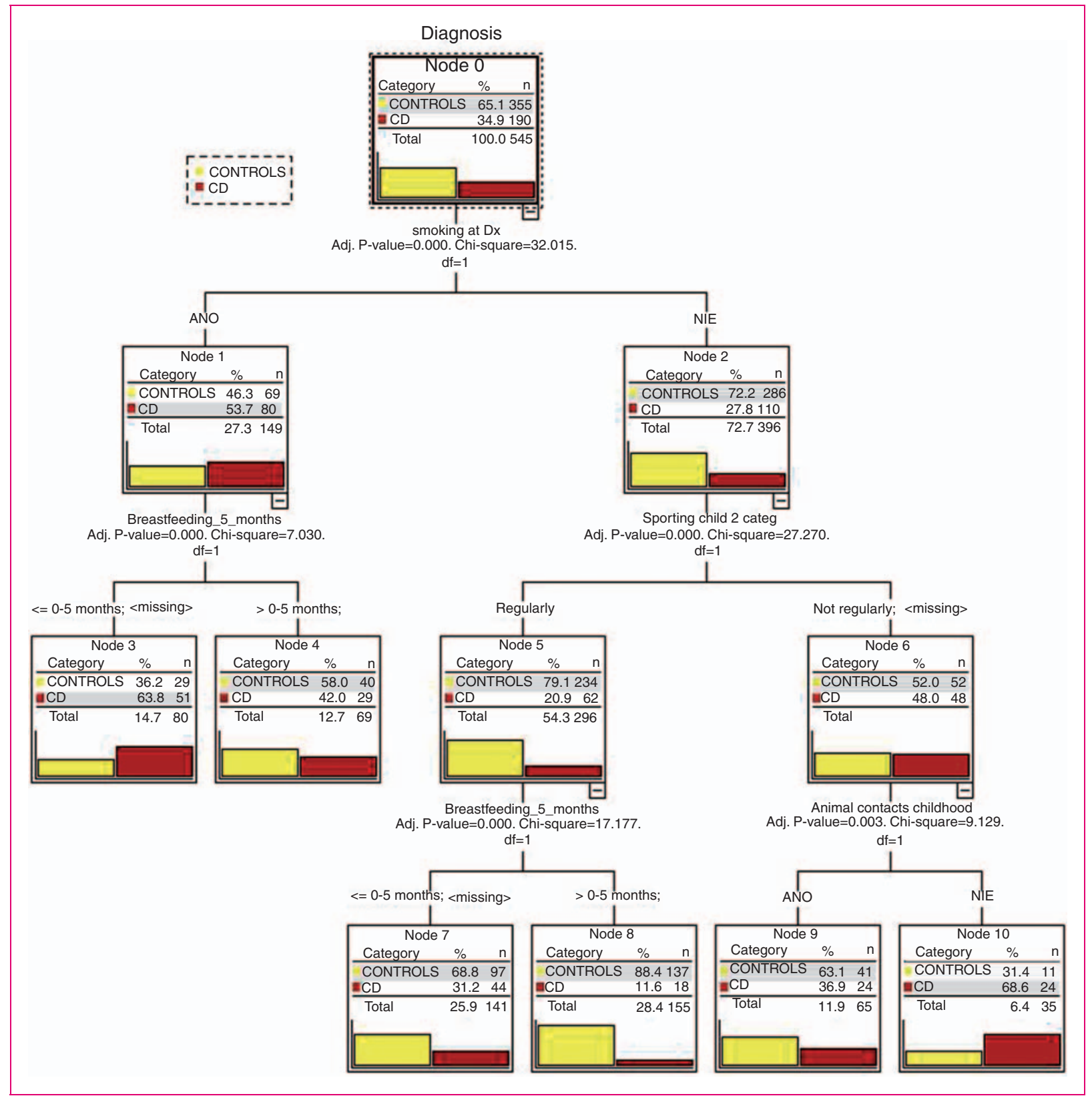

Figure 3. Results of multivariate classification tree analysis of the Crohn's disease and control groups.

ANO, yes; CD, Crohn's disease; Adj. P value, $p$-value adjusted after Bonferroni correction; df, degrees of freedom; Dx, diagnosis; NIE, no; Breastfeeding_5_months, Breastfed for less than or equal to 5 months (less than 6 months); Sporting child 2 categ, less than two sporting activities per week in childhood; Animal contacts childhood, contact with animals in childhood at least once per week.

present study. While Sonnenberg ${ }^{10}$ found that IBD associated with sedentary professions, such as administrative work, sales work, hair dressing, or health professions, ${ }^{10}$ this observation was not confirmed in a large prospective Danish population study. ${ }^{23}$ A study by Persson et al. ${ }^{24}$ revealed that the relative risk (RR) of $\mathrm{CD}$ related inversely to regular physical activity: for weekly and daily exercise, the estimated RRs were 0.6 $(95 \%$ CI $0.4-0.9)$ and $0.5 \quad(95 \%$ CI $0.3-0.9)$, respectively. Similar observations were reported also by Klein et al. in an Israeli study. ${ }^{25}$ Regular physical activity has a complex positive effect on a person's health: it increases the muscular mass and strength, improves bone density, improves cardiovascular and pulmonary functions, enhances immune system parameters, and eliminates the negative effects of stress on the organism. ${ }^{26,27}$ The mechanism by which sporting protects from IBD is not known. 
Table 6. Multivariate logistic regression of environmental factors associated with ulcerative colitis

\begin{tabular}{|c|c|c|c|c|c|c|c|}
\hline \multirow[b]{2}{*}{ Step } & \multirow[b]{2}{*}{ Variables } & \multirow[b]{2}{*}{ B } & \multirow[b]{2}{*}{ SE } & \multirow[b]{2}{*}{$p$-value } & \multirow{2}{*}{$\begin{array}{l}\text { OR } \\
(\operatorname{Exp}(B))\end{array}$} & \multicolumn{2}{|c|}{$95 \% \mathrm{Cl}$ for $\operatorname{EXP}(\mathrm{B})$} \\
\hline & & & & & & Lower & Upper \\
\hline \multirow[t]{7}{*}{ Step $1 \mathrm{a}$} & Breastfed for less than 6 months & 0.500 & 0.258 & 0.053 & 1.650 & 0.994 & 2.740 \\
\hline & Less than two sporting activities per week in childhood & 0.670 & 0.295 & 0.023 & 1.953 & 1.095 & 3.484 \\
\hline & Number of siblings & -0.037 & 0.102 & 0.716 & 0.964 & 0.789 & 1.177 \\
\hline & Size of the family in childhood & -0.200 & 0.095 & 0.036 & 0.819 & 0.680 & 0.987 \\
\hline & Appendectomy & 0.022 & 0.535 & 0.967 & 1.023 & 0.358 & 2.919 \\
\hline & Number of cigarettes per day at diagnosis & 0.027 & 0.019 & 0.170 & 1.027 & 0.989 & 1.067 \\
\hline & Constant & 0.179 & 0.679 & 0.792 & 1.196 & & \\
\hline \multirow[t]{4}{*}{ Step $4 a$} & Breastfed for less than 6 months & 0.526 & 0.257 & 0.041 & 1.692 & 1.022 & 2.801 \\
\hline & Less than two sporting activities per week in childhood & 0.687 & 0.293 & 0.019 & 1.988 & 1.119 & 3.534 \\
\hline & Size of the family in childhood & -0.202 & 0.095 & 0.033 & 0.817 & 0.679 & 0.984 \\
\hline & Constant & 0.244 & 0.380 & 0.520 & 1.277 & & \\
\hline
\end{tabular}

Step 1a, input-independent variables; Step 4a, output-independent variables; B, coefficient in the correlation equation; SE, standard error of B; $p$, level of statistical significance for a particular factor; $\mathrm{OR}$, odds ratio, $\mathrm{Cl}$, confidence interval for the odds ratio.

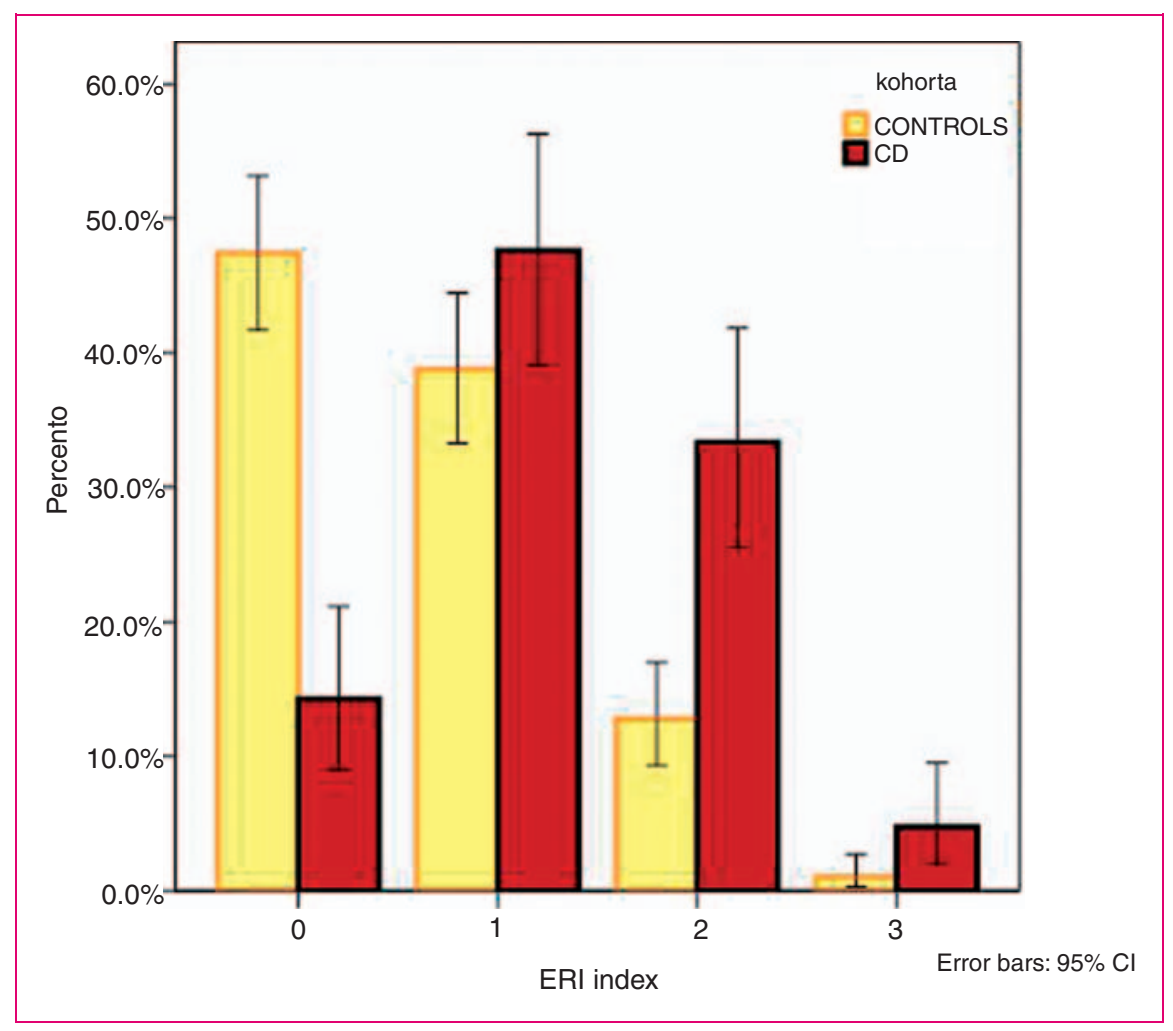

Figure 4. Frequencies of environmental risk indices (ERI) 0, 1, 2, and 3 in the control and Crohn's disease (CD) cohorts.

\section{Breastfeeding}

Being breastfed for less than 6 months was a risk factor for both CD (OR 2.7) and UC (OR 1.7). This finding is in line with that of a meta-analysis of 17 published studies on breastfeeding and IBD that showed protective effect of breastfeeding with a cumulative OR of 0.67 (95\% CI $0.52-0.86)$ for CD and an OR of $0.77(95 \%$ CI
0.61-0.96) for UC. ${ }^{28}$ However, in a subgroup of studies that were of the highest methodological quality, the observed protective effect was even higher: the OR for CD was 0.45 (95\% CI $0.26-0.79)$, while that for UC was $0.56(95 \%$ CI $0.38-0.81)$. Another two recent studies have also confirmed the link between short breastfeeding and IBD..$^{29,30}$ However, another recent large multicentre study from southern Italy found no 
Table 7. Theoretical prevalence of CD in ERI subgroups on the basis of the observed ERI index frequencies and the prevalence of CD in Slovakia

\begin{tabular}{|c|c|c|c|c|c|}
\hline \multirow[b]{2}{*}{$\begin{array}{l}\text { ERI } \\
\text { index }\end{array}$} & \multicolumn{2}{|c|}{ Frequency of $E R I^{a}$} & \multicolumn{3}{|c|}{ In ERI subgroup } \\
\hline & $\begin{array}{l}\text { Healthy } \\
\text { controls }\end{array}$ & $\begin{array}{l}\text { CD } \\
\text { group }\end{array}$ & $\begin{array}{l}\text { Healthy } \\
\text { controls }^{b}\end{array}$ & $\begin{array}{l}C D \\
\text { patients }^{b}\end{array}$ & $\begin{array}{l}\text { Calculated } \\
\text { prevalence } \\
\text { of } C D^{C}\end{array}$ \\
\hline 0 & 47 & 14 & 47,385 & 14 & 30 \\
\hline 1 & 39 & 48 & 38,762 & 48 & 124 \\
\hline 2 & 13 & 33 & 12,762 & 33 & 259 \\
\hline 3 & 1 & 5 & 991 & 5 & 505 \\
\hline Total & 100 & 100 & $99,900^{d}$ & $100^{d}$ & \\
\hline
\end{tabular}

${ }^{\mathrm{a}}$ Frequencies (\%) based on the observed frequencies among controls and CD group in this study.

${ }^{b}$ Calculated number of persons in ERI subgroup, which is based on the frequencies of ERI and prevalence of CD in Slovakia.

' $n$ per 100,000 .

dEstimated prevalence of Crohn's disease in Slovakia per 100,000.

$C D$, Crohn's disease; ERI, environmental risk index.

association whatsoever. ${ }^{31}$ The mechanism by which breastfeeding protects from IBD is not precisely known. It may help to optimize the gut microflora of the infant, promote the maturation of the mucosal immune system and intestinal mucosa, and have positive psychological and emotional effects.

\section{Contact with animals}

Infrequent contact with animals in childhood (defined as less than once per week) was another independent risk factor for $\mathrm{CD}$ (OR 1.7), but not for $\mathrm{UC}$, in the present study. In the univariate analyses, this association was significant for contact with cats, dogs, and cattle. These observations are consistent with the results of several large studies. A large German paediatric study on 444 patients with CD, 304 patients with UC, and 1260 control subjects revealed that contact with animals in early childhood had a significant protective effect (for CD: OR 0.5, 95\% CI 0.3-0.8; for UC: OR $0.3,95 \%$ CI $0.2-0.6)$. This effect was even stronger in the subgroup of children who had frequent contact with animals in the first year of life. Similar to the present results, particularly contact with cats and cattle had a significant protective effect. Another case-control study from Canada on 581 patients with IBD and 433 controls also revealed that contact with animals, particularly cats, was protective in CD (OR 0.66, 95\% CI $0.46-0.96$ ) but not UC. ${ }^{32}$

\section{Size of family}

The remaining risk factor that associated significantly with $\mathrm{UC}$, but not $\mathrm{CD}$, was the size of the household in childhood (OR 0.81 per person of the family, 95\% CI 0.68-0.98). Bernstein et al. ${ }^{32}$ made similar observations and recorded an OR of 0.87 (95\% CI 0.79-0.96). This association may reflect the fact that larger families impose more intensive antigenic stimulation in early childhood due to more interpersonal contacts. This may promote the maturation of the immune system.

\section{Combination of environmental risk factors}

In this study, we designed a composite environmental index called the ERI that was composed of the three variables that associated most significantly with $C D$ in multivariate analyses, namely smoking at diagnosis, being breastfed for less than 6 months, and less than two sporting activities per week in childhood. The use of this index revealed that $47 \%$ of the controls but only $14 \%$ of the patients with CD had no risk factors, whereas $14 \%$ of the controls and $38 \%$ of the patients with $\mathrm{CD}$ had at least two risk factors. These differences were highly statistically significant. Furthermore, calculation of the theoretical prevalence of $\mathrm{CD}$ based on the observed ERI prevalence in the controls and the ORs revealed that the prevalence of CD rose as the number of risk factors increased, namely, from 30 $(E R I=0)$ to $124(E R I=1), 259(E R I=2)$, and 505 $(E R I=3)$. This suggests that the increase in CD prevalence in Western countries may be attributable to the increased prevalence of several (possibly three) environmental risk factors. ERI was a working tool in our study and its composition may but does not have to reflect a definite true combination of environmental risk factors resulting in $\mathrm{CD}$. Further studies are necessary.

\section{Clinical implications}

The clinical significance of the present study lies in its contribution to explaining the causes of IBD. If these factors are confirmed prevention strategies in high-risk groups (such as children with a positive family history or genetic or serological surrogate markers) may reduce their development of IBD. Indeed, the present study suggests that modifying all four environmental risk factors (namely, smoking, breastfeeding, sporting activity, and contact with animals) may reduce the risk of developing IBD very significantly (by 10-30 times). Further research is needed to confirm and expand the models presented in this study.

\section{Funding}

This work was supported by the Ministry of Health of Slovak Republic (2007/19-UK-02). 


\section{Conflict of interest}

The authors declare that there is no conflict of interest.

\section{References}

1. Mayer L. Evolving paradigms in the pathogenesis of IBD. Journal of Gastroenterology 2010; 45: 9-16.

2. Noomen CG, Hommes DW and Fidder HH. Update on genetics in inflammatory disease. Best Practice and Research. Clinical Gastroenterology 2009; 23: 233-243.

3. Barrett JC, Hansoul S, Nicolae DL, et al. Genome-wide association defines more than 30 distinct susceptibility loci for Crohn's disease. Nature Genetics 2008; 40: 955-962.

4. Cornish JA, Tan E, Simillis C, et al. The risk of oral contraceptives in the etiology of inflammatory bowel disease: a meta-analysis. American Journal of Gastroenterology 2008; 103: 2394-2400.

5. Malekzadeh F, Alberti C, Nouraei M, et al. Crohn's disease and early exposure to domestic refrigeration. PLoS One 2009; 4: e4288.

6. Lakatos PL, Szamosi T and Lakatos L. Smoking in inflammatory bowel diseases: good, bad or ugly? World Journal of Gastroenterology 2007; 13: 6134-6139.

7. Lengen C, Regard M, Joller H, et al. Anomalous brain dominance and the immune system: do left-handers have specific immunological patterns? Brain and Cognition 2009; 69: 188-193.

8. Korzenik JR. Past and current theories of etiology of IBD: toothpaste, worms, and refrigerators. Journal of Clinical Gastroenterology 2005; 39: S59-S65.

9. Koutroubakis IE, Vlachonikolis IG and Kouroumalis EA. Role of appendicitis and appendectomy in the pathogenesis of ulcerative colitis: a critical review. Inflammatory Bowel Diseases 2002; 8: 277-286.

10. Sonnenberg A. Occupational distribution of inflammatory bowel disease among German employees. Gut 1990; 31: 1037-1040.

11. Reif S, Klein I, Lubin F, et al. Pre-illness dietary factors in inflammatory bowel disease. Gut 1997; 40: 754-760.

12. Mahid SS, Minor KS, Soto RE, et al. Smoking and inflammatory bowel disease: a meta-analysis. Mayo Clinic Proceedings 2006; 81: 1462-1471.

13. Silverberg MS, Satsangi J, Ahmad T, et al. Toward an integrated clinical, molecular and serological classification of inflammatory bowel disease: report of a Working Party of the 2005 Montreal World Congress of Gastroenterology. Canadian Journal of Gastroenterology 2005; 19(Suppl A): 5-36.

14. Breinman L, Friedman JH, Olshen RA, et al. Classification and regression trees. Wadsworth \& Brooks/Cole Advanced Books, 1984.

15. Corrao G, Tragnone A, Caprilli R, et al. Risk of inflammatory bowel disease attributable to smoking, oral contraception and breastfeeding in Italy: a nationwide case-control study. Cooperative Investigators of the Italian Group for the Study of the Colon and the Rectum (GISC). International Journal of Epidemiology 1998; 27: 397-404.

16. Baron S, Turck D, Leplat C, et al. Environmental risk factors in paediatric inflammatory bowel diseases: a population based case control study. Gut 2005; 54: 357-363.

17. Radon K, Windstetter D, Poluda AL, et al. Contact with farm animals in early life and juvenile inflammatory bowel disease: a case-control study. Pediatrics 2007; 120: 354-361.

18. Hafner S, Timmer A, Herfarth $\mathrm{H}$, et al. The role of domestic hygiene in inflammatory bowel diseases: hepatitis A and worm infestations. European Journal of Gastroenterology and Hepatology 2008; 20: 561-566.

19. Coughlin SS. Recall bias in epidemiologic studies. Journal of Clinical Epidemiology 1990; 43: 87-91.

20. Katschinski B, Fingerle D, Scherbaum B, et al. Oral contraceptive use and cigarette smoking in Crohn's disease. Digestive Diseases and Sciences 1993; 38: 1596-1600.

21. King Jr TE, Savici D and Campbell PA. Phagocytosis and killing of Listeria monocytogenes by alveolar macrophages: smokers versus nonsmokers. Journal of Infectious Diseases 1988; 158: 1309-1316.

22. Rubin DT and Hanauer SB. Smoking and inflammatory bowel disease. European Journal of Gastroenterology and Hepatology 2000; 12: 855-862.

23. Boggild H, Tuchsen F and Orhede E. Occupation, employment status and chronic inflammatory bowel disease in Denmark. International Journal of Epidemiology 1996; 25: 630-637.

24. Persson PG, Leijonmarck CE, Bernell O, et al. Risk indicators for inflammatory bowel disease. International Journal of Epidemiology 1993; 22: 268-272.

25. Klein I, Reif S, Farbstein H, et al. Preillness non dietary factors and habits in inflammatory bowel disease. Italian Journal of Gastroenterology and Hepatology 1998; 30: 247-251.

26. Narula $\mathrm{N}$ and Fedorak RN. Exercise and inflammatory bowel disease. Canadian Journal of Gastroenterology 2008; 22: 497-504.

27. Brolinson PG and Elliott D. Exercise and the immune system. Clinics in Sports Medicine 2007; 26: 311-319.

28. Klement E, Cohen RV, Boxman J, et al. Breastfeeding and risk of inflammatory bowel disease: a systematic review with meta-analysis. American Journal of Clinical Nutrition 2004; 80: 1342-1352.

29. Hansen TS, Jess T, Vind I, et al. Environmental factors in inflammatory bowel disease: a case control study based on a Danish inception cohort. Journal of Crohns and Colitis 2011; 5: 577-584.

30. Gearry RB, Richardson AK, Frampton CM, et al. Population-based cases control study of inflammatory bowel disease risk factors. Journal of Gastroenterology and Hepatology 2010; 25: 325-333.

31. Castiglione F, Diaferia M, Morace F, et al. Risk factors for inflammatory bowel diseases according to the 'hygiene hypothesis': a case-control, multi-centre, prospective study in Southern Italy. Journal of Crohns and Colitis 2012; 6: 324-329.

32. Bernstein CN, Rawsthorne P, Cheang M, et al. A population-based case control study of potential risk factors for IBD. American Journal of Gastroenterology 2006; 101: 993-1002. 